\title{
The Importance of Anatomic Configuration and Cystic Changes in Macular Hole: Predicting Surgical Success with a Different Approach
}

Yücel Ozturk ( $\square$ yucellozturk@yahoo.com )

Haydarpasa Numune Egitim ve Arastirma Hastanesi: Istanbul Haydarpasa Numune Egitim ve Arastirma Hastanesi https://orcid.org/0000-0002-8520-0073

Abdullah Ağın ( $\square$ abdullahagin@gmail.com)

Haseki Training and Research Hospital: Istanbul Haseki Egitim Ve Arastirma Hastanesi https://orcid.org/0000-0001-7173-8617

\section{Nadir Kockar}

Haydarpasa Numune Egitim ve Arastirma Hastanesi: Istanbul Haydarpasa Numune Egitim ve Arastirma Hastanesi

\section{Nevzat Ay}

Haydarpasa Numune Egitim ve Arastirma Hastanesi: Istanbul Haydarpasa Numune Egitim ve Arastirma Hastanesi

\section{Serhat Imamoglu}

Haydarpasa Numune Egitim ve Arastirma Hastanesi: Istanbul Haydarpasa Numune Egitim ve Arastirma Hastanesi

\section{Alev Ozcelik Kose}

Haydarpasa Numune Egitim ve Arastirma Hastanesi: Istanbul Haydarpasa Numune Egitim ve Arastirma Hastanesi

\section{Süleyman Kugu}

Haydarpasa Numune Egitim ve Arastirma Hastanesi: Istanbul Haydarpasa Numune Egitim ve Arastirma Hastanesi

\section{Research Article}

Keywords: area index, macular hole, cyst area, vitrectomy, type 1 closure, type 2 closure

Posted Date: January 25th, 2022

DOI: https://doi.org/10.21203/rs.3.rs-1265203/v2

License: (c) (i) This work is licensed under a Creative Commons Attribution 4.0 International License. Read Full License 


\section{Abstract}

\section{Purpose}

This study aimed to define novel metrics for the area of the macular hole $(\mathrm{MH})$ and the cysts placed around the hole using an optical coherence tomography (OCT) device.

\section{Methods}

This retrospective, cross-sectional study was conducted with 58 eyes of 56 patients. The patients were divided into two groups according to anatomic closure after surgery. The novel metrics including macular hole index (MHI), tractional hole index (THI), and (hole forming factor) HFF, macular hole area (HA), the cystoid space areas in the inner retinal layers (CA), and the cyst hole area index (CHAl) were calculated. Correlation of the $\mathrm{CA}$, the $\mathrm{HA}$, and the CHAl with other indexes was assessed. Receiver operating characteristic (ROC) curves and cut-off values were derived for indexes predicting type 1 or type 2 closures.

Results

The CA positively correlated with the base $\mathrm{MH}$ size and the maximum $\mathrm{MH}$ height $(p<0.001, p<0.001$, respectively). The HA showed a positive correlation with basal $\mathrm{MH}$ size, minimum $\mathrm{MH}$ size, and maximum MH height $(p<0.001, p<0.001, p<0.001$, respectively). CHAl was positively correlated with minimum MH size. $(p=0.02)$. CHAl and HA were negatively correlated with postoperative BCVA $(p=0.003$, $p=0.006$, respectively). ROC curve analysis showed that MHI, THI, and HFF predicted type 1 closure; on the other hand, $\mathrm{CHAl}$ and $\mathrm{HA}$ predicted type 2 closures.

\section{Conclusions}

$\mathrm{MHI}$ and our novel index $\mathrm{CHAl}$, which can be calculated without any additional software, could successfully predict type 1 and type 2 closures, respectively.

\section{Key Messages}

$\mathrm{MHI}$, which reflects the height of the macular hole, is the most important biomarker with high sensitivity and specificity in predicting type 1 closure. Our novel index, $\mathrm{CHAl}$, obtained by dividing the macular hole area by the cystoid space areas in the inner retinal layers, is a strong predictor for type 2 closure. The presence of cystoid space areas in the inner retinal layers emerges as a factor preventing Type 2 closure.

\section{Introduction}

The macular hole $(\mathrm{MH})$ is an anatomical opening formed in the center of the fovea [1]. It is a treatable cause of central vision loss, which is more common in older people[2,3]. Recent studies have determined that posterior vitreous detachment (PVD), which causes anteroposterior vitreomacular traction, is 
responsible for $\mathrm{MH}$ formation[4-7]. Since Kelly and Wendel managed to close the $\mathrm{MH}$ with pars plana vitrectomy (PPV), surgical success has increased remarkably with the new techniques developed up to $75 \%-95 \%[8]$. The success of the surgery defined by Kang et al. was divided into two groups according to the type of $\mathrm{MH}$ closure. Type 1 closure is described as a normal foveal contour without interruption in the foveal tissue's continuity above the retinal pigment epithelial layer [9]. On the contrary, in type 2 closures, there is an interruption in the continuity of the foveal tissue, and there is no retinal tissue above the retinal pigment epithelial layer [9]. The MH margin is thin and attached to the underlying retinal pigment epithelial layer [10].

In various clinicopathological studies, the closure of $\mathrm{MH}$ centrifugal displacement of photoreceptors from the foveal center, rearrangement of foveal depression, and glial proliferation of Müller cells has been demonstrated [11-14]. Although, lower disease stage, younger patient, duration of symptoms, secondary (retinal detachment, myopia, macular telangiectasia, trauma, optic pit) or idiopathic nature, its chronicity, vertical metamorphopsia, the experience of the surgeon and the preoperative visual acuity reflecting the stability of the outer retinal structures are the factors affecting the surgical success, understanding the detailed anatomical configuration of $\mathrm{MH}$ and its clarification with the help of advanced technology will bring a new approach to this issue which factors are influential on the surgical success[1].

Optical coherence tomography (OCT) provides better recognition of MH's and evaluation of foveal structures. Various OCT parameters are typically analyzed to estimate the visual and anatomical outcomes after $\mathrm{MH}$ repair. These metrics include the minimum distance between the $\mathrm{MH}$ edges, the maximum diameter at the apex of the $\mathrm{MH}$, the base $\mathrm{MH}$ size, and $\mathrm{MH}$ height. Various indexes have been developed to estimate the results of these OCT measurements, including hole form factor (HFF), MH index (MHI), and tractional hole index (THI)[15-18]. At the same time, some studies have evaluated the $\mathrm{MH}$ area $(\mathrm{HA})$ as well as the cyst areas around $\mathrm{MH}(\mathrm{CA})$ by subjecting OCT images to analysis using different software, such as Image $J$, which has many disadvantages $[19,20]$.

Histopathologic studies of autopsy eyes with $\mathrm{MH}$ show intraretinal alteration surrounding $\mathrm{MH}$, including cystic retinal edema and deterioration of the photoreceptor layer[21]. However, the effect of cystic changes on the anatomic and functional success of the surgery is not fully elucidated. In this study, we measured the aforementioned new metrics, including CHAl, with the OCT device without additional software and investigated the effect of $\mathrm{MH}$ configuration and cystic alterations on anatomical and functional results with a different unique perspective.

\section{Materials And Methods}

This study is a retrospective, cross-sectional, single-center case study. Fifty-eight eyes of 56 patients who underwent 23-gauge PPV with the diagnosis of idiopathic $\mathrm{MH}$ in the ophthalmology clinic of the tertiary university hospital between 2016 and 2020 were included in the study. Subjects who underwent PPV and internal limiting membrane peeling for idiopathic $\mathrm{MH}$ and a minimum of 6 months of postoperative follow-up were included in this study. Exclusion criteria were traumatic MH's, patients with diabetes 
mellitus or hypertension-induced retinopathy, history of vitreous surgery or retinal detachment surgery, high myopia (including axial length greater than $26.00 \mathrm{~mm}$ or $-6.00 \mathrm{D}$ refractive error), uveitis history, any fundus disease other than $\mathrm{MH}$, history of intravitreal injection, and any ocular pathology other than concomitant visually significant cataract.

Relevant clinical and surgical history information was collected. All patients included in the study underwent a comprehensive ophthalmologic examination, including best-corrected visual acuity (BCVA), as measured on a Snellen eye chart, was recorded preoperatively and at the last visit and converted to logarithms of minimum angle resolution (log MAR) acuities, slit-lamp biomicroscopy, dilated fundus examination, and OCT. Full-thickness MH was defined using the spectral domain OCT criteria in the International Vitreomacular Traction Study [20]. After surgery, patients were divided into two types of anatomical outcomes: Type 1, where the $\mathrm{MH}$ is entirely closed, and type 2, in which the $\mathrm{MH}$ does not close with the absence of the foveal area of the neurosensory retina.

\section{Surgical steps}

Surgery was performed using a standard 3-port, 23-gauge pars plana vitrectomy. When a cataract was present, a combined phacovitrectomy was performed. Twenty-three-gauge trocar cannulas were placed $3.5 \mathrm{~mm}$ posterior to the limbus. Patients underwent PPV and internal limiting membrane peeling surgery. The posterior hyaloid was wholly detached from the retina after the core vitrectomy. The brilliant blue injection was applied to visualize the internal limiting membrane in the macular region, and the internal limiting membrane was peeled off. Liquid-air exchange was performed, and the air in the vitreous cavity was replaced with $20 \%$ sulfur hexafluoride. After surgery, patients were advised to stay in the prone position for one week.

\section{OCT measurements}

Spectralis SD-OCT (Spectralis; Heidelberg Engineering, Heidelberg, Germany) was used for OCT imaging. Spectralis SD-OCT incorporates real-time eye-tracking software and has the advantage of improving quality and segmentation accuracy in the macular region. OCTs at all visits (before MH formation, during $\mathrm{MH}$ formation, and after vitrectomy) were reviewed. Macular scans and 25 horizontal B scans centered on the fovea were performed. The area to be measured was taken from the 12th or 13th images that exactly centered the macula. The caliper function in the device's software was used in the measurement. Images with an image quality score above 20 were used in patients without cataracts. A lower quality score of 15 was chosen in preoperative OCT images in patients with cataracts, and the images with the highest quality score were evaluated.

Basal $\mathrm{MH}$ size, minimum $\mathrm{MH}$ size, $\mathrm{MH}$ height, right and left arm length, $\mathrm{CA}$, and $\mathrm{HA}$ were measured using the device's internal measurement function in OCT images. According to the measurements, previously reported MHI, HFF, and THI were calculated. MHI was defined as the ratio of the $\mathrm{MH}$ height to the $\mathrm{MH}$ bottom diameter, and $\mathrm{THI}$ was defined as the ratio of the $\mathrm{MH}$ height to the narrowest diameter of the $\mathrm{MH}$. HFF was calculated by taking the sum of the lengths of the nasal and temporal arms and dividing by the 
longest base diameter of $\mathrm{MH}$. CHAl was found by dividing the HA by CA. Measurements were made at different times by two different observers (YO, NK). The measurement technique of HA and CA is shown in Figure 1. Each index was measured twice by the observers and averaged. The mean of the two observers' measurements was then used for statistical analysis. To evaluate the reproducibility of the measurements before analysis, for each measured section, inter-examiner ICC was greater than 0.90 (95\% confidence interval 0.90-0.92).

\section{Statistical analysis}

The data were analyzed with the SPSS 16.0 (SPSS Inc., Chicago, IL, USA) program. Data distribution was analyzed with the Shapiro-Wilk test. The Mann-Whitney $U$ test was used to compare median values. Spearman correlation test, anatomical result, and different parameters such as basal MH size $(\mu \mathrm{m})$, minimum MH size $(\mu \mathrm{m})$, $\mathrm{MH}$ height $(\mu \mathrm{m}), \mathrm{CA}(\mathrm{mm} 2)$, and HA $(\mathrm{mm} 2)$ were used to analyze the correlation between the outcomes. A ROC curve analysis was performed to evaluate the predictive ability of the CA, $\mathrm{HA}$, and CHAl. The area under the ROC curve was calculated to evaluate the effectiveness of each parameter. The cut-off value was obtained from the ROC curve, and sensitivity and specificity were determined. A p-value $<0.05$ was considered statistically significant.

\section{Results}

In the study, which included 58 eyes of 56 patients, the mean age was $69.8 \pm 6.7$ (59-91) years, and the male to female ratio was 22:34. As a result of MH surgery, 37 (63.8\%) eyes were type 1, and $21(36.2 \%)$ patients had type 2 closures. The mean preoperative BCVA was $1.4 \pm 0.3 \log$ MAR, while the mean BCVA at the last postoperative follow-up was $0.9 \pm 0.5 \mathrm{log}$ MAR. Postoperative vision increased significantly ( $p$ $<0.001)$. An examination of the MH staging revealed that $22(37 \%)$ eyes were stage $2,8(13 \%)$ eyes were stage 3 , and $28(48 \%)$ eyes were stage 4 .

Postoperative BCVA was $0.65 \pm 0.4 \log$ MAR in type 1 closures and $1.3 \pm 0.44 \log$ MAR in type 2 closures. Visual acuity increased significantly when anatomical success was achieved in patients $(p<0.001)$. As shown in Table 1, there were statistically significant differences in type 1 closures compared to type 2 closures in OCT measurements, basal MH size, minimum MH size, maximum MH height, HFF, MHI, THI, $\mathrm{HA}$, and CHAl.

As shown in Table 2, the CA showed a positive correlation with base $\mathrm{MH}$ size and maximum $\mathrm{MH}$ height ( $\mathrm{r}$ $=0.624, p<0.001 ; r=0.722, p<0.001$, respectively). HA was positively correlated with base $\mathrm{MH}$ size, minimum MH size, and maximum MH height $(r=0.934, p<0.001 ; r=0.765, p<0.001 ; r=0.483 p<0.001$, respectively). HA were negatively correlated with postoperative BCVA, HFF, MHI, THI $(r=-0.357, p=0.006$; $r=-0.403, p=0.002 ; r=-0.673, p<0.001 ; r=-0.475, p<0.001$ respectively). CHAI was positively correlated with minimum $\mathrm{MH}$ size $(r=0.297, p=0.02)$. CHAl was negatively correlated with postoperative BCVA, maximum MH height, HFF, and THI $(r=-0.39, p=0.003 ; r=-0.604 p<0.001 ; r=-0.361, p=0.007 ; r=$ $-0.389, p=0.003$, respectively). 
ROC curve analysis revealed that MH indexes, such as MHI, THI, and HFF, successfully predicted type 1 closures, whereas HA and CHAl predicted type 2 closures. (Figure 2-3) For Type 1 closures, higher AUC $(>0.5)$ values of MHI (0.823), THI (0.750), and HFF (0.722) were recorded. Higher AUC $(>0.5)$ values of HA (0.709) and $\mathrm{CHAl}(0.769)$ were recorded for type 2 closures. We found $75 \%$ sensitivity and $75 \%$ specificity for $\mathrm{MHI}$, frequently used to predict type 1 closures. In predicting type 2 closures, $77 \%$ sensitivity and $73 \%$ specificity were found for CHAl, with a cut-off value of 2.08 (Table 3).

\section{Discussion}

Recent advances in the visualization of the retina spearheaded by OCT technology will likely revolutionize the management of macular diseases today [22-24]. In this study, we investigated the effect of the preoperative OCT biomarkers on the surgical success of $\mathrm{MH}$ and brought a new understanding with a different horizon.

Hitherto, MHI, THI and HFF indices have been evaluated in many studies to measure success in $\mathrm{MH}$ surgery. $[15,16,25,18,26] \mathrm{MHI}, \mathrm{THI}$ represents the effect of putative tangential, anteroposterior vitreomacular tractions and retinal hydration on MH development $[15,16]$. HFF reflects whether the bilateral detached photoreceptor layer is long enough to cover the exposed RPE layer[18]. Liu et al. [25] evaluated $\mathrm{MHI}, \mathrm{THI}$, and $\mathrm{MHCl}(\mathrm{HFF})$ in 165 eyes of 164 patients with $\mathrm{MH}$. Patients were divided into three according to the degree of postoperative anatomic closure. [A (bridge-like closure), B (good closure), and C (poor closure or no closure)]. It has been reported that only $\mathrm{MHCl}$ (HFF) can predict anatomical success (cut-off value 0.7 for $A$ and $1.00 \mathrm{for} B$ ) [25]. This study did not specify which stage of $\mathrm{MH}$ was evaluated. Moreover, minimum, and basal $\mathrm{MH}$ diameters were not investigated, and the correlations of these parameters with these $\mathrm{MH}$ diameters are unclear [25]. On the other hand, Wakely et al.[18] evaluated the minimum linear diameter, preoperative basal diameter $\mathrm{MH}, \mathrm{MHI}, \mathrm{HFF}$, and THI indices in 50 patients undergoing $\mathrm{MH}$ surgery. Similar to our study, preoperative basal diameter and minimum linear diameter were found to be associated with anatomical and functional success [18]. However, since no significant difference could be found for MHI, HFF, and THI, it was stated that these indices did not have a real advantage in evaluating anteroposterior and tangential tractions of $\mathrm{MH}$. Only four patients (8\%) were operated on for stage $4 \mathrm{MH}$ in this study. In our series, the number of patients operated on for stage $4 \mathrm{MH}$ was $28(48 \%)$.

Meanwhile, Yu et al.[26] compared these indices in stage 3 and stage $4 \mathrm{MH}$ and showed that HFF and THI were higher in patients with stage $3 \mathrm{MH}$, but $\mathrm{MHI}$ was similar between the two groups. However, they postulated that patients with stage $3 \mathrm{MH}$ had a lower duration of symptoms and smaller $\mathrm{MH}$ diameters than those of stage 4; when it comes to $\mathrm{MH}$ with a diameter greater than $400 \mu \mathrm{m}$, holes of the two stages were similar in clinical features and morphological parameters, on the other hand, the design of the study did not include the effects of these indices on surgical success. [26]. Briefly, our findings show that greater $\mathrm{MHI}, \mathrm{THI}$, and HFF were associated with type 1 closure (reflecting the surgical success), especially in stage $4 \mathrm{MH}$, which characterized greater $\mathrm{MH}$ diameters, full separation of posterior vitreous detachment, and maximum efficacity anteroposterior and tangential tractions. Moreover, $\mathrm{MHI}$ and THI 
were found to be more sensitive and specific than HFF in predicting type 1 closure. This statement proves that the force of anteroposterior tractions, which is the cornerstone of the $\mathrm{MH}$ pathogenesis, symbolizes $\mathrm{MH}$ height rather than nasal and temporal arm height. Archimedes stated that the moment of force applied to the object is $\mathrm{M}=\mathrm{rxF}$, where $\mathrm{F}$ is the applied force, and $\mathrm{r}$ is the distance of the applied force from the object. The r-value is highest at the apex of $\mathrm{MH}$. The moment obtained at the apex of $\mathrm{MH}$, which is characterized mainly by the $\mathrm{MH}$ height, reaches its maximum. Type 1 closure chance increases when anteroposterior tractions, which represent $\mathrm{MH}$ height, are removed by surgery, and vision reaches the desired maximum level with the resolution of cystic areas.

To the best of our knowledge, the information about the relationship between cystic space and hole area of $\mathrm{MH}$ are scarce in the literature. In our study, we found that our novel index CHAl predicted type 2 closure with high sensitivity $(77 \%)$ and specificity (\%73) compared to those of HA ( $p=0.001)$. Besides, $\mathrm{CHAl}$ and HA have negatively correlated with postoperative BCVA. The fact that greater HA indicates that the tractional forces affecting $\mathrm{MH}$ are stronger, the stage of $\mathrm{MH}$ is advanced, and chronicity of the case, and this situation is related to the lack of benefit from the surgery for obvious reasons explained as expected. As mentioned above, CHAl is obtained by dividing HA by CA. The critical point on this issue is the lower $\mathrm{CA}$ increased the $\mathrm{CHAl}$, making it a more sensitive and specific index for predicting type 2 closure compared to HA. From this point of view, CA may be considered as a factor preventing surgical failure. Additionally, CA shows a high correlation with maximum $\mathrm{MH}$ height, which is the most important predictive parameter which we supposed for type 1 closure $(r=0.722, p<0.001)$. Venkatesh et al. [27] evaluated various indices in 49 patients with idiopathic full-thickness $\mathrm{MH}$ and showed that the $\mathrm{MH}$ cystoid space area index, which is obtained by dividing the macular hole cystoid space area by the total area, is predictive for type 1 closure. However, horizontal $\mathrm{MH}$ parameters (base $\mathrm{MH}$ size, minimum $\mathrm{MH}$ size, and maximum $\mathrm{MH}$ height) were not evaluated in this study. Furthermore, 20 (41\%) of the cases were failed after the first surgery and underwent a second procedure with silicone tamponade or gas. These results were discussed, ignoring the possible effects of silicone on the retina. In our cases, standard $\mathrm{MH}$ surgery procedure was applied in parallel with the other studies, and $20 \%$ sulfur hexafluoride was used in all cases.

In a recent study conducted by Joo et al.[28] investigated the effect of intraretinal cyst specifications (width, height, diagonal length, angle) on predicting $\mathrm{MH}$ closure and showed that intraretinal cyst height was greater in type 1 closure compared to those of type 2 closure. Our results are supported by these studies. In response to retinal injuries or pathologies, there is an activation of Muller cells characterized by reactive gliosis, which is the basis of the pathogenesis of $\mathrm{MH}$ closure with hypertrophy, proliferation, and upregulation of glial fibrillary acidic protein (GFAP). Romano et al.[29] compared the GFAP immunoreactivity and OCT parameters of idiopathic epiretinal membranes and diabetic epiretinal membranes. They found the number of intraretinal cysts and GFAP immunoreactivity in the diabetic epiretinal membrane to be higher than those of the idiopathic group. Due to the possible contribution of intraretinal cysts to GFAP production, CA may be thought of as a preventive factor for type 2 closure. We think that our novel index CHAl can be used more distinctive than HA, which is widely known in the literature and is associated with type 2 closure. 
ImageJ program, which has many disadvantages, is widely used for image processing. Image processing requires a complex multi-step procedure. In addition, the use of different software for these measurements causes loss of both personnel, time in the transfer and evaluation of OCT images. Such losses are avoided by using the tools already installed in the OCT program. Meanwhile, in order for OCT images to be evaluated optimally in different programs, the resolutions must be adjusted correctly. In our study, measurements were calculated directly using the own module of the OCT device without using any program.

There are some limitations, including retrospective nature, relatively small sample size, and the cases could not be evaluated longitudinally. Besides, it is unclear when the changes in intraretinal cystoid spaces and OCT parameters occur and how they progress over time.

\section{Conclusion}

$\mathrm{MHI}$ is the most important biomarker with high sensitivity and specificity in predicting type 1 closure. Our novel index, CHAl is a strong predictor for type 2 closure. Extended evaluation $\mathrm{MH}$ parameters will establish the value of understanding anatomic configuration and cystic changes as an important biomarker for predicting successful closure. Further research with an extended cohort and automated measurements, leveraging the advantage of the advancement of machine learning concurrently with a prolonged follow-up, are essential to validate our results and assess the value of the biomarkers for understanding the pathophysiology of $\mathrm{MH}$.

\section{Declarations}

\section{Compliance with ethical standards}

\section{Funding}

This study was funded by the authors and did not receive any grant from finance agencies in the public or commercial sectors.

\section{Conflict of interest}

The authors declare that they have no conflict of interest.

\section{Ethical approval}

This study protocol was approved by Haydarpasa Numune Training and Research Hospital Clinical Research Ethics Committee (2021/216-3405)

\section{Informed consent}

Informed consent was waived due to the retrospective nature of this study. 


\section{References}

1. Parravano M, Giansanti F, Eandi CM, Yap YC, Rizzo S, Virgili G (2015) Vitrectomy for idiopathic macular hole. Cochrane Database Syst Rev (5):CD009080. doi:10.1002/14651858.CD009080.pub2

2. Wang S, Xu L, Jonas JB (2006) Prevalence of full-thickness macular holes in urban and rural adult Chinese: the Beijing Eye Study. Am J Ophthalmol 141 (3):589-591. doi:10.1016/j.ajo.2005.10.021

3. Jackson TL, Donachie PHJ, Sparrow JM, Johnston RL (2013) United Kingdom National Ophthalmology Database study of vitreoretinal surgery: report 2, macular hole. Ophthalmology 120 (3):629-634. doi:10.1016/j.ophtha.2012.09.003

4. Hee MR, Puliafito CA, Wong C, Duker JS, Reichel E, Schuman JS, Swanson EA, Fujimoto JG (1995) Optical coherence tomography of macular holes. Ophthalmology 102 (5):748-756. doi:10.1016/s01616420(95)30959-1

5. Johnson MW, Van Newkirk MR, Meyer KA (2001) Perifoveal vitreous detachment is the primary pathogenic event in idiopathic macular hole formation. Arch Ophthalmol 119 (2):215-222

6. Van Newkirk MR, Johnson MW, Hughes JR, Meyer KA, Byrne SF (2000) B-scan ultrasonographic findings in the stages of idiopathic macular hole. Trans Am Ophthalmol Soc 98:163-169; discussion 169171

7. Smiddy WE, Flynn HW, Jr. (2004) Pathogenesis of macular holes and therapeutic implications. Am J Ophthalmol 137 (3):525-537. doi:10.1016/j.ajo.2003.12.011

8. Kelly NE, Wendel RT (1991) Vitreous surgery for idiopathic macular holes. Results of a pilot study. Arch Ophthalmol 109 (5):654-659. doi:10.1001/archopht.1991.01080050068031

9. Kang SW, Ahn K, Ham DI (2003) Types of macular hole closure and their clinical implications. Br J Ophthalmol 87 (8):1015-1019. doi:10.1136/bjo.87.8.1015

10. Xia S, Zhao XY, Wang EQ, Chen YX (2019) Comparison of face-down posturing with nonsupine posturing after macular hole surgery: a meta-analysis. BMC Ophthalmol 19 (1):34. doi:10.1186/s12886019-1047-8

11. Funata M, Wendel RT, de la Cruz Z, Green WR (1992) Clinicopathologic study of bilateral macular holes treated with pars plana vitrectomy and gas tamponade. Retina 12 (4):289-298. doi:10.1097/00006982-199212040-00001

12. Madreperla SA, Geiger GL, Funata M, de la Cruz Z, Green WR (1994) Clinicopathologic correlation of a macular hole treated by cortical vitreous peeling and gas tamponade. Ophthalmology 101 (4):682-686. doi:10.1016/s0161-6420(94)31278-4 
13. Nork TM, Ghobrial MW, Peyman GA, Tso MO (1986) Massive retinal gliosis. A reactive proliferation of Muller cells. Arch Ophthalmol 104 (9):1383-1389. doi:10.1001/archopht.1986.01050210137041

14. Rosa RH, Jr., Glaser BM, de la Cruz Z, Green WR (1996) Clinicopathologic correlation of an untreated macular hole and a macular hole treated by vitrectomy, transforming growth factor-beta 2 , and gas tamponade. Am J Ophthalmol 122 (6):853-863. doi:10.1016/s0002-9394(14)70382-4

15. Kusuhara S, Teraoka Escano MF, Fujii S, Nakanishi Y, Tamura Y, Nagai A, Yamamoto H, Tsukahara Y, Negi A (2004) Prediction of postoperative visual outcome based on hole configuration by optical coherence tomography in eyes with idiopathic macular holes. Am J Ophthalmol 138 (5):709-716. doi:10.1016/j.ajo.2004.04.063

16. Ruiz-Moreno JM, Staicu C, Pinero DP, Montero J, Lugo F, Amat P (2008) Optical coherence tomography predictive factors for macular hole surgery outcome. Br J Ophthalmol 92 (5):640-644. doi:10.1136/bjo.2007.136176

17. Ullrich S, Haritoglou C, Gass C, Schaumberger M, Ulbig MW, Kampik A (2002) Macular hole size as a prognostic factor in macular hole surgery. Br J Ophthalmol 86 (4):390-393. doi:10.1136/bjo.86.4.390

18. Wakely L, Rahman R, Stephenson J (2012) A comparison of several methods of macular hole measurement using optical coherence tomography, and their value in predicting anatomical and visual outcomes. Br J Ophthalmol 96 (7):1003-1007. doi:10.1136/bjophthalmol-2011-301287

19. Goto K, Iwase T, Yamamoto K, Ra E, Terasaki H (2020) Correlations between intraretinal cystoid cavities and pre- and postoperative characteristics of eyes after closure of idiopathic macular hole. Sci Rep 10 (1):2310. doi:10.1038/s41598-020-59295-7

20. Duker JS, Kaiser PK, Binder S, de Smet MD, Gaudric A, Reichel E, Sadda SR, Sebag J, Spaide RF, Stalmans P (2013) The International Vitreomacular Traction Study Group classification of vitreomacular adhesion, traction, and macular hole. Ophthalmology 120 (12):2611-2619.

doi:10.1016/j.ophtha.2013.07.042

21. Guyer DR, Green WR, de Bustros S, Fine SL (1990) Histopathologic features of idiopathic macular holes and cysts. Ophthalmology 97 (8):1045-1051. doi:10.1016/s0161-6420(90)32465-x

22. Avci R, Mavi Yildiz A, Yilmaz S (2021) Conventional internal limiting membrane peeling versus temporal inverted internal limiting membrane flap for large macular holes. Eur J Ophthalmol 31 (2):679687. doi:10.1177/1120672119892427

23. Yilmaz Tugan B, Karabas L, Yenihayat F, Subasi S, Kesim E, Ozkan B (2020) Correlation of Visual Recovery and Increased Ellipsoid Zone Reflectivity After Successful Macular Hole Surgery. Turk J Ophthalmol 50 (5):283-287. doi:10.4274/tjo.galenos.2020.21456 
24. Gunay BO, Erdogan G (2021) Evaluation of Macular Changes in the Long Term after Pars Plana Vitrectomy with Internal Limiting Membrane Peeling for Diabetic Macular Edema. Ophthalmologica 244 (3):237-244. doi:10.1159/000514992

25. Liu P, Sun Y, Dong C, Song D, Jiang Y, Liang J, Yin H, Li X, Zhao M (2016) A new method to predict anatomical outcome after idiopathic macular hole surgery. Graefes Arch Clin Exp Ophthalmol 254 (4):683-688. doi:10.1007/s00417-015-3116-x

26. Yu Y, Liang X, Wang Z, Wang J, Liu W (2018) Clinical and morphological comparisons of idiopathic macular holes between stage 3 and stage 4. Graefes Arch Clin Exp Ophthalmol 256 (12):2327-2333. doi:10.1007/s00417-018-4158-7

27. Venkatesh R, Mohan A, Sinha S, Aseem A, Yadav NK (2019) Newer indices for predicting macular hole closure in idiopathic macular holes: A retrospective, comparative study. Indian J Ophthalmol 67 (11):1857-1862. doi:10.4103/ijo.IJO_364_19

28. Joo JH, Nam WH, Joo T, Moon SW (2022) Role of intraretinal cysts in the prediction of postoperative closure and photoreceptor damages of the idiopathic full-thickness macular hole. BMC Ophthalmol 22 (1):5. doi:10.1186/s12886-021-02204-x

29. Romano MR, Ilardi G, Ferrara M, Cennamo G, Allegrini D, Pafundi PC, Costagliola C, Staibano S, Cennamo G (2018) Intraretinal changes in idiopathic versus diabetic epiretinal membranes after macular peeling. PLoS One 13 (5):e0197065. doi:10.1371/journal.pone.0197065

\section{Tables}

Table 1. Macular hole indexes between the two types of macular hole closures were analysed using the MannWhitney U test 


\begin{tabular}{llcl} 
Variable & Type 1 closure & Type 2 closure & p value \\
\hline Preoperative BCVA $($ log MAR) & $1.31 \pm 0.35$ & $1.55 \pm 0.38$ & 0.01 \\
\hline Postoperative BCVA $(\log \mathrm{MAR})$ & $0.65 \pm 0.4$ & $1.3 \pm 0.44$ & $<0.001^{*}$ \\
\hline Base MH size $(\mu \mathrm{m})$ & $977 \pm 342$ & $1355 \pm 544$ & $0.003^{*}$ \\
\hline Minimum MH size $(\mu \mathrm{m})$ & $400 \pm 196$ & $599 \pm 226$ & $0.001^{*}$ \\
\hline Maximum hole height $(\mu \mathrm{m})$ & $504 \pm 107$ & $476 \pm 177$ & $0.04^{*}$ \\
\hline HFF & $0.84 \pm 0.19$ & $0.68 \pm 0.18$ & $0.006^{*}$ \\
\hline MHI & $0.56 \pm 0.20$ & $0.39 \pm 017$ & $<0.001^{*}$ \\
\hline THI & $1.8 \pm 1.6$ & $1.02 \pm 0.85$ & $0.001^{*}$ \\
\hline CA $\left(\mathrm{mm}^{2}\right)$ & $0.17 \pm 009$ & $0.15 \pm 0.17$ & 0.136 \\
\hline MHA $\left(\mathrm{mm}^{2}\right)$ & $0.29 \pm 0.11$ & $0.41 \pm 0.24$ & $0.03^{*}$ \\
\hline CHAI & $2.07 \pm 1.15$ & $5.21 \pm 5.83$ & $0.001^{*}$ \\
\hline
\end{tabular}

Mann-Whitney U test, *statistically significant, BCVA = Best corrected visual acuity, $\mathrm{MH}=\mathrm{Macular}$ hole, $\mathrm{HFF}=$ Hole forming factor, $\mathrm{MHI}=$ Macular hole index, THI=Tractional hole index, CA=Cysts area, HA= Hole area, $\mathrm{CHAI}=$ Cyst hole area index

Table 2. Results of correlation coefficient between intraretinal cystoid space area, hole area and cyst hole area index and other preoperative variables.

\begin{tabular}{lllllll} 
& CA & \multicolumn{3}{c}{ HA } & \multicolumn{3}{c}{ CHAI } \\
\cline { 2 - 7 } Variable & $\mathbf{r}$ & p value & $\mathbf{r}$ & p value & r & p value \\
\hline Postoperative BCVA & 0.124 & 0.35 & -0.357 & $0.006^{*}$ & -0.39 & $0.003^{*}$ \\
Base MH size $(\mu \mathrm{m})$ & 0.624 & $<0.001^{*}$ & 0.934 & $<0.001^{*}$ & 0.05 & 0.93 \\
\hline Minimum MH size $(\mu \mathrm{m})$ & 0.252 & 0.056 & 0.765 & $<0.001^{*}$ & 0.297 & $0.02^{*}$ \\
\hline Maximum MH height $(\mu \mathrm{m})$ & 0.722 & $<0.001^{*}$ & 0.483 & $<0.001^{*}$ & -0.604 & $<0.001^{*}$ \\
\hline HFF & 042 & 0.75 & -0.403 & $0.002^{*}$ & -0.361 & $0.007^{*}$ \\
\hline MHI & -0.181 & 0.17 & -0.673 & $<0.001^{*}$ & -0.257 & 0.058 \\
\hline THI & 0.3 & 0.82 & -0.475 & $<0.001^{*}$ & -0.389 & $0.003^{*}$ \\
\hline
\end{tabular}

Spearman correlation test, ${ }^{*}$ statistically significant, BCVA = Best corrected visual acuity, MH= Macular hole, $\mathrm{HFF}=$ Hole forming factor, $\mathrm{MHI}=$ Macular hole index, THI=Tractional hole index, CA=Cysts $\operatorname{area}\left(\mathrm{mm}^{2}\right), \mathrm{HA}^{2}$ Hole area $\left(\mathrm{mm}^{2}\right), \mathrm{CHAI}=$ Cyst hole area index 


\begin{tabular}{llllll} 
Variable & AUROC & Cut-off value & Sensitivity (\%) & Specificity (\%) & P \\
\hline Tip 1 closure & & & & & \\
\hline HFF & 0.722 & 0.742 & 64 & 60 & $0.006^{*}$ \\
MHI & 0.823 & 0.436 & 75 & 75 & $0.000^{*}$ \\
\hline THI & 0.750 & 0.984 & 73 & 65 & $0.002^{*}$ \\
\hline Tip 2 Closure & & & & & 0.513 \\
\hline CA & 0.445 & 0.135 & 62 & 57 & $0.012^{*}$ \\
HA & 0.709 & 0.305 & 77 & 73 & $0.001^{*}$ \\
\hline CHAI & 0.769 & 2.08 & 77 & &
\end{tabular}

*statistically significant, $\mathrm{HFF}=$ Hole forming factor, $\mathrm{MHI}=$ Macular hole index, THI=Tractional hole index, $\mathrm{CA}=$ Cysts area, $\mathrm{HA}=$ Hole area, $\mathrm{CHAI}=$ Cyst hole area index

\section{Figures}

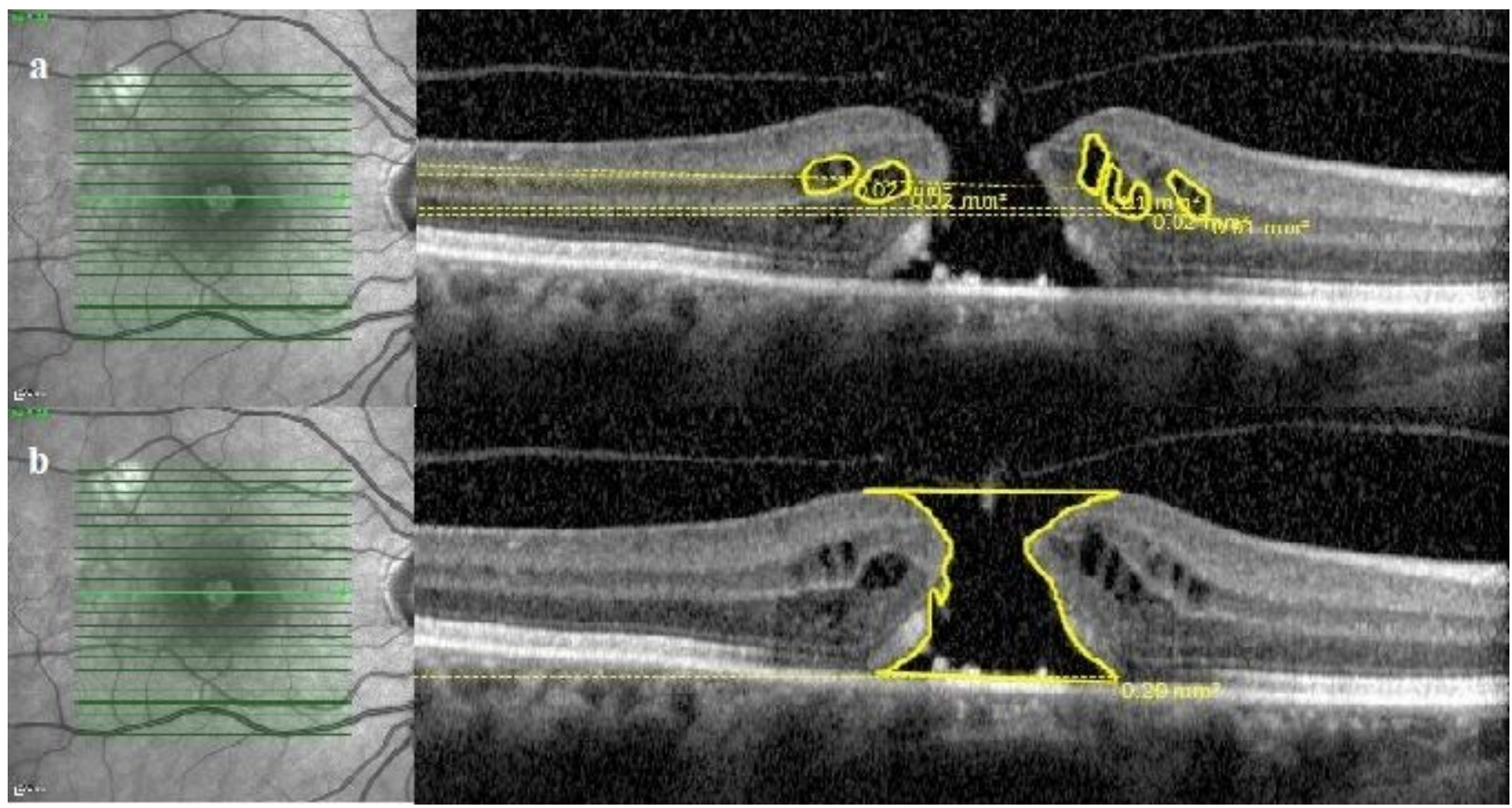

Figure 1

Preoperative OCT image (a) area of the cysts around the hole (CA) and (b) the area of the hole (HA) 


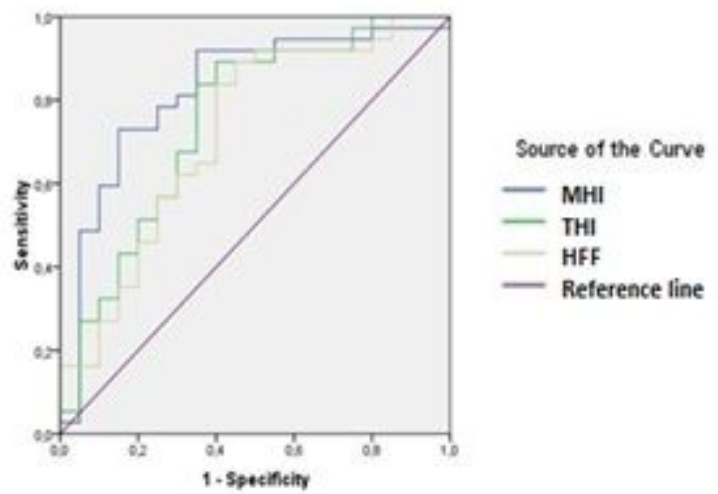

Figure 2

ROC analysis graphics of HFF, THI, MHI for type 1 closure

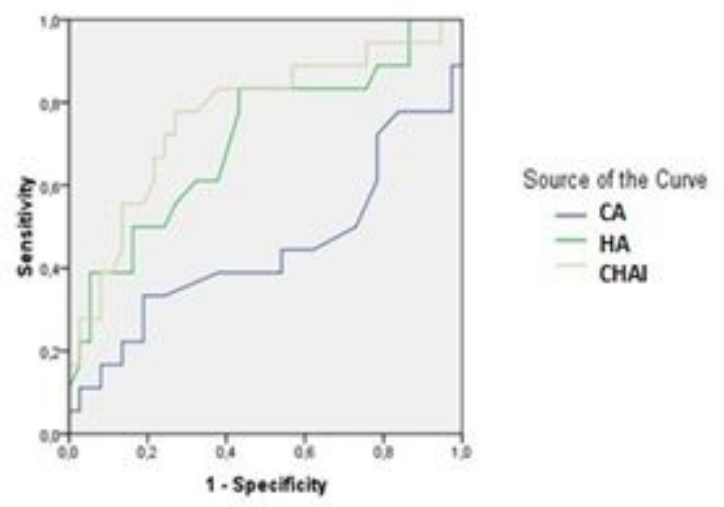

Figure 3

ROC analysis graphics of CA, HA, CHAl for type 2 closure 